\title{
PENGARUH LINGKUNGAN KERJA, PENGHARGAAN (REWARD) DAN PUNISHMENT TERHADAP KINERJA KARYAWAN (Studi Kasus Pada PT. Socfhindo Divisi IV Afdheling Seleleh)
}

\author{
Safwan Kamal ${ }^{1}$, Mutia Sumarni ${ }^{2}$, Widia Wati ${ }^{3}$
}

\begin{abstract}
ABSTRAK
Lingkungan kerja, penghargaan (reward) dan punishment merupakan faktor yang penting untuk menunjang kinerja sekaligus memberi dorongan bagi karyawan untuk meningkatkan semangat dalam bekerja. Penelitian ini bertujuan untuk mengetahui pengaruh lingkungan kerja, penghargaan (reward) dan punishment terhadap kinerja karyawan. Penelitian ini menggunakan penarikan sampel probability sampling dan menentukan jumlah sampel dari suatu populasi menggunakan simple random sampling dimana setiap anggota populasi mempunyai peluang yang sama untuk dipilih menjadi anggota sampel berdasarkan kriteria tertentu sesuai dengan kriteria yang dilakukan peneliti. Sampel yang ditentukan yaitu 63 responden. Hasil penelitian ini menunjukkan bahwa terdapat pengaruh lingkungan kerja yang positif dan signifikan terhadap kinerja karyawan dilihat dari nilai ( $t$ hitung, 2,696 > 2,00100 ( $t$ tabel) dengan tingkat sig. 0.003 $<0,05$. Variabel penghargaan (reward) berpengaruh positif dan signifikan terhadap kinerja karyawan yang dilihat dari nilai ( $t$ hitung) 3,257 > 2,00100 ( $t$ tabel) dengan tingkat sig. $0.002<0.05$. Variabel punishment berpengaruh positif dan signifikan terhadap kinerja karyawan yang dilihat dari nilai ( $t$ hitung) 3,638 > 2,00100 ( $t$ tabel) dengan tingkat sig. $0.004<0.05$. terdapat pengaruh secara simultan antara lingkungan kerja, penghargaan (reward) dan punishment hal ini dilihat dari $F$ hitung $(5,122)$ lebih besar dari $F$ tabel $(2,76)$ dengan tingkat signifikan $0.003<0,05$
\end{abstract}

Kata Kunci : Lingkungan Kerja, Penghargaan (reward), Punishment, Kinerja.

\section{ABSTRACT}

Work environment, reward (reward) and punishment are important factors to support performance as well as encourage employees to increase morale at work. This study aims to determine the effect of the work environment, reward (reward) and punishment on employee performance. This study uses probability sampling and determines the number of samples from a population using simple random sampling where each member of the population has an equal chance of being selected as a sample member

\footnotetext{
${ }^{1}$ Institut Agama Islam Negeri Langsa/ safwankamal@iainlangsa.ac.id

${ }^{2}$ Institut Agama Islam Negeri Langsa/ meutiasumarni@gmail.com

${ }^{3}$ Institut Agama Islam Negeri Langsa/widia4175@gmail.com
} 
based on certain criteria in accordance with the criteria set by the researcher. The sample specified was 63 respondents. The results of this study indicate that there is a positive and significant work environment influence on employee performance seen from the value ( $t$ count) 2,696>2,00100 (t table) with sig level. $0.003<0.05$. The reward variable has a positive and significant effect on employee performance as seen from the value ( $t$ count) 3.257> 2.00100 ( $t$ table) with the sig level. $0.002<0.05$. The punishment variable has a positive and significant effect on employee performance as seen from the value ( $t$ count) 3,638>2,00100 ( $t$ table) with the sig level. $0.004<0.05$. There is a simultaneous influence between the work environment, reward (reward) and punishment, this can be seen from the F count (5.122) greater than F table (2.76) with a significant level of $0.003<0.05$.

Keywords: Work Environment, Reward, Punishment, Performance.

\section{PENDAHULUAN}

Pemerintah memiliki peran penting dalam pembangunan di era globalisasi (Budiman, Kamal, \& Tarlis, 2019). Globalisasi merupakan suatu proses pergerakan ekonomi yang dinamis dimana hambatan, dampak, dan proteksi terhadap industri sudah semakin berkurang yang mengakibatkan persaingan yang pesat antara perusahaanperusahaan yang sudah ada untuk dapat bertahan dan bersaing dalam bidang usaha, tidak terkecuali dalam bidang sektor barang maupun jasa masalah Sumber Daya Manusia menjadi sorotan utama bagi perusahan untuk tetap bertahan di era globalisasi ini. Salah satu industri yang terus bertahan dan bersaing dalam era ini yaitu Industri Kelapa sawit. Kelapa sawit merupakan industri yang bergerak dibidang perkebunan kelapa sawit yang mana jumlah perusahaannya adalah yang paling banyak di indonesia

\section{Gambar 1.}

\section{Jumlah Perusahaan Perkebunan Besar Menurut Jenis Tanaman}

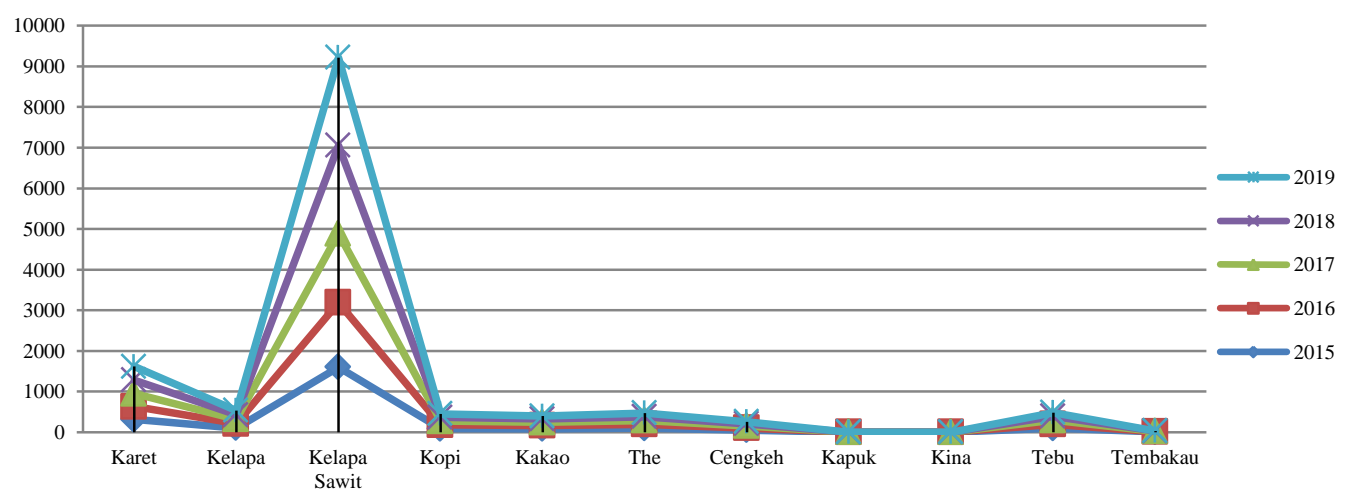

Sumber: Badan Pusat Statistik, 2019 
Berdasarkan survey tahun 2015-2019 yang dilakukan Badan Pusat Statistik yang tersebar diseluruh indonesia, jumlah perusahaan perkebunan kelapa sawit terus mengalami peningkatan tiap tahunnya. Hingga tahun 2019, jumlah perusahaan perkebunan kelapa sawit mencapai 2.165 dan yang terbanyak di Indonesia.

Gambar. 2

\section{Perkembangan Produksi Kelapa Sawit (ton) Tahun 2015-2019}

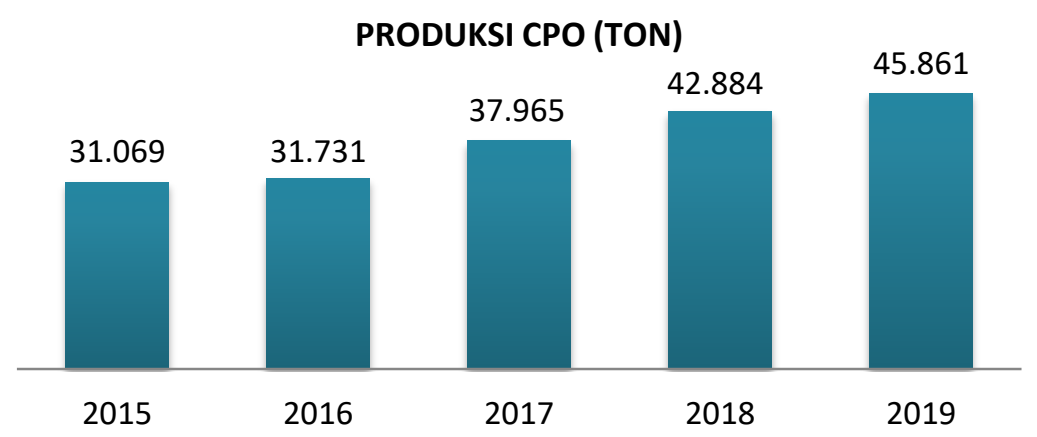

Sumber: Statistik Perkebunan Indonesia Komoditas Kelapa Sawit, Direktorat Jenderal Perkebunaan, 2019

Berdasarkan dari hasil survey tersebut bahwa produksi kelapa sawit mengalami peningkatan tiap tahunnya. Perkembangan produksi kelapa sawit di Indonesia mengalami peningkatan yang tinggi pada tahun 2019 yaitu sebanyak 45.861 ton/tahun.

Berdasarkan hasil survey awal yang dilakukan oleh peneliti dengan menyebarkan kuesioner terhadap 63 responden, yaitu karyawan Pt. Socfhindo Divisi IV menunjukkan bahwa tingkat kinerja karyawan Pt. Socfhindo Divisi IV Afdheling Seleleh sebesar 77,4 $\%$ hal ini menunjukkan bahwa tingkat kinerja karyawan Pt. Socfhindo Divisi IV Afdheling Seleleh tergolong sedang.

Kinerja karyawan adalah unsur penting bagi perusahaan, Kinerja merupakan hasil pekerjaan seorang karyawan selama periode tertentu dibandingkan dengan berbagai kemungkinan seperti, standar, target/sasaran maupun kriteria yang telah ditentukan terlebih dahulu dan telah disepakati bersama (Kaswan, 2016). Terciptanya kinerja pegawai/karyawan yang tinggi sangatlah tidak mudah, dikarenakan kinerja karyawan dapat timbul apabila organisasi mampu menciptakan kondisi yang dapat mendorong dan memungkinkan karyawan untuk mengembangkan dan meningkatkan kemampuan serta keterampilan yang dimiliki secara optimal sehingga karyawan dapat memberikan kontribusi yang bagi perusahaan. Kinerja menurut Mangkunegara adalah hasil kerja secara kualitas dan kuantitas yang dicapai oleh seorang karyawan dalam melaksanakan 
tugasnya sesuai dengan tanggung jawab yang diberikan kepadanya.( Mangkunegara, 2001).

Disamping kinerja karyawan, dalam teori factor lingkungan kerja juga memiliki peran penting dalam perusahaan, lingkungan kerja adalah yang menggambarkan sehat/baik atau tidak baiknya sebuah organisasi non profit dibidang pemerintahan, dapat diartikan sebagai segala sesuatu yang ada disekitar pegawai/karyawan, yang langsung atau tidak langsung berpengaruh pada pelaksanaan pekerjaannya. (Sumantri, 2016).

Definisi lain menjelaskan bahwa lingkungan kerja yaitu segala sesuatu yang ada disekitar para pekerja, yang dapat mempengaruhi dirinya dalam menjalankan tugastugas yang dibebankan. Apabila kondisi lingkungan kerja yang baik meningkatkan semangat dalam bekerja yang memungkinkan akan berpengaruh terhadap kinerja karyawan dan apabila kondisi lingkungan kerja yang nyaman akan mempengaruhi karyawan bekerja lebih giat dan konsentrasi menyelesaikan tugas-tugasnya sesuai jadwal. (Nitisemito, 2012)

Kondisi kerja adalah keadaan dimana tempat kerja yang baik meliputi lingkungan fisik dan lingkungan non fisik yang dapat memberikan kesan menyenangkan, aman, tentram, dan lain sebagainya. Namun berdasarkan hasil observasi awal yang dilakukan oleh peneliti pada kenyataannya masih ada karyawan yang kurang nyaman dan aman dilingkungan kerja walaupun sudah ditempatkan dilingkungan kerja dan rekan kerja yang dapat membantu pekerjaan agar dapat mencapai target yang ditetapkan perusahaan.

Namun, untuk membantu karyawan dalam mencapai target yang ditetapkan, perusahaan telah memberikan penghargaan (reward) kepada para karyawan. Reward adalah timbal balik yang diberikan organisasi kepada karyawan ketika mereka telah melakukan tindakan atau tugas yang diberikan organisasi. (Puwanenthiren, P, 2011). Penghargaan (reward) dapat dibagi menjadi dua macam, yaitu Penghargaan sosial (social rewards) dan Penghargaan psikis (psychic rewards) (Mahmudi, 2009).

Dengan adanya penghargaan (reward) yang tinggi dari perusahaan, diharapkan karyawan akaan lebih mencintai pekerjaannya, sanggup bekerja dengan baik, dan memiliki loyalitas yang tinggi serta berkeinginan untuk melakukan kinerja yang lebih baik sehingga dapat menjadi pendorong seseorang dalam melaksanakan suatu pekerjaan secara maksimal dan juga untuk lebih meningkatkan semangat kerja karyawan. (Raja Ali, 2011)

Penghargaan (reward) adalah ganjaran, hadiah, penghargaan atau imbalan yang bertujuan agar seseorang menjadi lebih giat lagi usahanya untuk memperbaiki atau meningkatkan kinerja yang telah dicapai. karyawan terhadap sistem pembagian penghargaan, dimana penghargaan dibagikan dengan secara bergilir. Namun, penghaargaan yang di danberikan hanya berupa uang dan jabatan, sedangkan beberapa karyawan lainnya juga menginginkaan penghargaan dalam bentuk keagamaan seperti haji dan umrah. 
Lingkungan kerja merupakan faktor kenyaman, keamanan dan ketentraman bagi karyawan dalam bekerja, sedangkan reward dan punishment merupakan suatu cara yang dapat diberlakukan untuk karyawan agar dapat memperbaiki sikap dan perilaku yang menyimpang dan tidak sesuai dengan peraturan yang ada di perusahaan, sedangkan Punishment (Hukuman) adalah suatu perbuatan yang kurang menyenangkan, yaitu berupa ancaman hukuman yang diberikan kepada karyawan secara sadar dan sengaja dengan tujuan untuk memperbaiki karyawan yang melanggar dan memberikan pelajaran agar tidak mengulangi kesalahannya. Punishmet merupakan bentuk hukuman negatif yang diberikan perusahaan, tetapi jika diberikan secara tepat dan bijak bisa memberikan motivasi bagi katyawan untuk meningkatkan kinerjanya. (Purnama, Ade Vici, 2017). Adapun secara garis besar, Punishment dapat dibedakan menjadi dua bentuk, yaitu: Punishment Preventif dan Punishment Represif (Purwanto, M.N, 2009)

Semakin berat punishment (hukuman) yang diberikan perusahaan maka akan membuat sejumlah karyawan takut untuk melanggarnya, serta akan membuat sikap dan perilaku indisipliner karyawan akan berkurang dan hal ini membuat para karyawan akan lebih berhati-hati dalam bekerja dan menyebabkan mereka kurang maksimal dalam bekerja terutama dalam kehadiran (kedisiplin), pemanfaatan waktu dan kurangnya kerjasama antar karyawan

Berdasarkan dari beberapa masalah di atas, meka penelitian ini hendak mengurai bagaimana pengaruh lingkungan kerja, penghargaan (Reward) Dan Punishment terhadap kinerja karyawan (Studi Kasus Pada Pt. Socfhindo Divisi IV Afdheling Seleleh)".

\section{METODE PENELITIAN}

Penelitian ini menggunakan metode kuantitatif dengan menekankan pada pengujian teori melalui pengukuran variabel penelitian dengan angka dan melakukan analisis data dengan prosedur statistik (SPSS). Teknik pengumpulan data yang digunakan adalah angket, daftar wawancara, dan pengisian angket (kuesioner). Jenis dan sumber data yang digunakan adalah data primer dan data sekunder. Dalam proses pengambilan data Teknik yang digunakan dalam penelitian ini ditentukan dengan menggunakan teknik probability sampling dan dengan memakai Metode Simple Random Sampling. Dikatakan simpel (sederhana) karena pengambilan anggota sampel dari populasi dilakukan secara acak tanpa memperhatikan strata yang ada dalam populasi itu. Sampel acak (probabilitas) adalah suatu metode pemilihan ukuran sampel dimana setiap anggota populasi mempunyai peluang yang sama untuk dipilih menjadi anggota sampel.

Pengukuran variabel lingkungan kerja, penghargaan (reward), dan Punishment akan menggunakan skala likert dengan tahapan-tahapan uji validitas, uji reliabilitas dan uji asumsi klasik sebelum menganalisis dengan regresi berganda. 


\section{HASIL DAN PEMBAHASAN}

Berdasarkan pengujian variabel dengan analisis regresi berganda, dengan melibatkan variable yang diteliti yakni lingkungan kerja (X1), penghargaan (reward) (X2), punishment (X3) dan kinerja karyawan (Y).maka penelitian ini menemukan bahwa :

\section{Tabel.1}

\section{Uji Analisis Regresi Berganda}

\section{Coefficients \\ Model}

$\begin{array}{llll} & & & \\ & & & \\ & & & \\ & & & \\ & \text { (Constant) } & 8,284 & 4,945 \\ & \text { Lingkungan__ } & , 097 & , 139 \\ & \text { Kerja } & & \\ & \text { Penghargaan } & , 038 & , 149 \\ & \text { Punishment } & , 487 & , 134 \\ \text { a. Dependent Variable: Kinerja_Karyawan }\end{array}$

$\begin{array}{lll}\begin{array}{l}\text { Standard } \\ \text { ized } \\ \text { Coeffici } \\ \text { ents }\end{array} & \mathrm{t} & \text { Sig. } \\ \text { Beta } & & \\ & 5,675 & , 000 \\ , 086 & 2,696 & , 004 \\ & & \\ , 032 & 3,257 & , 002 \\ , 435 & 3,638 & , 004\end{array}$

Berdasarkan tabel coefficients di atas memberikan informasi tentang persamaan regresi ada tidaknya pengaruh dari variabel lingkungan kerja, penghargaan (reward) dan punishment terhadap variabel kinerja karyawan. Adapun rumus persamaan regresi dalam analisis penelitian ini adalah sebagai berikut;

$$
Y=8,284+0,097 X 1+0,038 X 2+0,487 X 3
$$

Persamaan di atas dapat dijelaskan bahwa diperoleh nilai konstanta sebesar 8,284 yang mengandung arti bahwa nilai konstanta variabel kinerja karyawan sebesar 8,284. Koefisien regrasi variabel kinerja karyawan melalui variabel lingkungan kerja diperoleh nilai sebesar 0,097. Koefisien regresi variabel kinerja karyawan melalui variabel penghargaan (reward) diperoleh nilai sebesar 0,038. Koefisien regresi variabel kinerja keuangan melalui variabel punishment diperoleh sebesar 0,487 .

Dalam melihat signifikansi variable secara parsial, maka peneliti melakukan uji parsial dimana Uji parsial digunakan untuk menunjukkan sebarapa jauh satu variabel independen secara individu (parsial) dalam menerangkan variasi variabel dependen. Adapun hasil uji parsial sebagai berikut : 
Tabel 2.

Hasil Uji T

\section{Coefficients $^{\mathrm{a}}$}

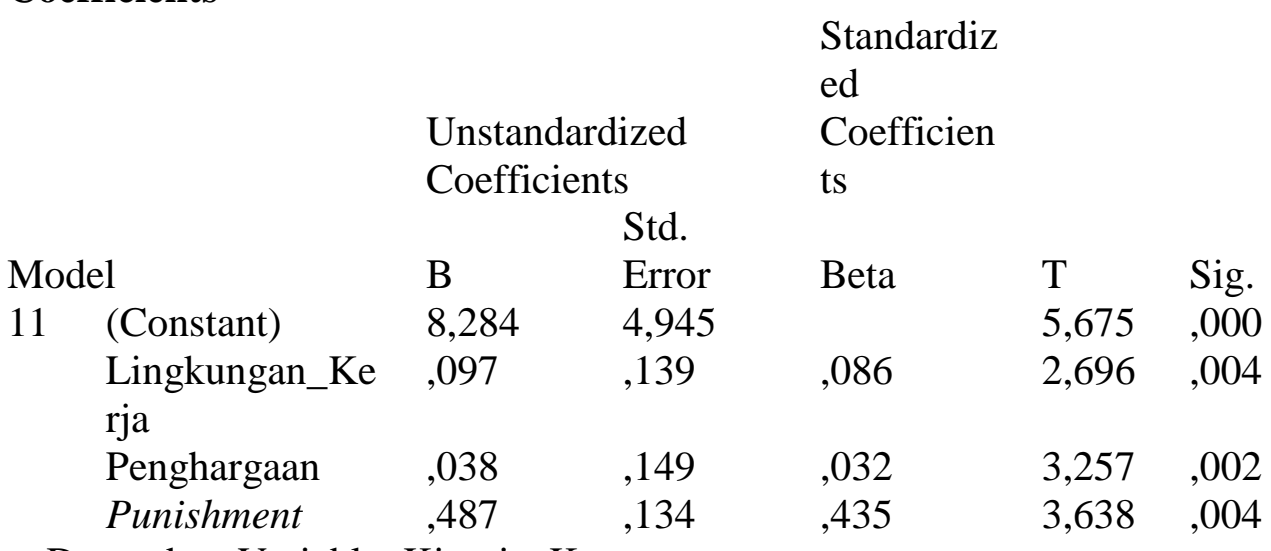

a. Dependent Variable: Kinerja_Karyawan

Sumber: data primer diolah, 2020.

Berdasarkan tabel uji $\mathrm{t}$ di atas diketahui bahwa jumlah variabel pada penelitian ini adalah 4 yaitu lingkungan kerja, penghargaan (reward), punishment dan kinerja keuangan atau $K=4$, Sementara jumlah sampel atau $N=63$, maka $(N-K)=(63-4=$ 59). Angka ini dilihat dari distribusi nilai $\mathrm{T}$ tabel maka diperoleh nilai $\mathrm{T}$ tabel adalah 2.00100 .

\section{Lingkungan kerja berpengaruh terhadap kinerja karyawan PT Socfindo Kebun Afdheling Seleleh Divisi IV}

Lingkungan kerja merupakan keadaan sekitar tempat kerja baik secara fisik maupun non-fisik yang dapat memberikan kesan yang menyenangkan, mengamankan, menentramkan, dan betah kerja. Lingkungan kerja yang kondusif memberikan rasa aman dan nyaman yang memungkinkan pegawai bekerja secara optimal. Lingkungan kerja dalam organisasi mempunyai arti penting bagi individu yang bekerja didalamnya, karena lingkungan kerja akan berpengaruh secara langsung maupun tidak langsung terhadap manusia yang ada didalamnya.

Hasil penelitian menunjukkan bahwa variabel lingkungan kerja berpengaruh positif terhadap kinerja karyawan PT Socfindo Kebun Afdheling Seleleh Divisi IV. Hal ini dibuktikan dari nilai sig variabel lingkungan kerja yakni $0.004<0.05$ (tingkat signifikansi), yang artinya bahwa pengaruh yang terjadi antara variabel lingkungan kerja dengan kinerja karyawan adalah signifikan secara statistik. Sedangkan nilai $t$ hitung 2,696>2,00100 ( $\mathrm{t}$ tabel), sehingga berpengaruh positif terhadap kinerja karyawan. Maka dapat disimpulkan pengaruh lingkungan kerja terhadap kinerja karyawan PT Socfindo Kebun Afdheling Seleleh Divisi IV bersifat positif dan signifikan yaitu $\mathrm{H}_{0} 1$ ditolak dan $\mathrm{H}_{\mathrm{a}} 1$ diterima. Penelitian ini menunjukkan bahwa lingkungan kerja yang nyaman menyebabkan karyawan meningkatkan kinerjanya dalam bekerja. 
Hasil penelitian ini mendukung penelitian yang dilakukan oleh Siti Nurhidayah, yang menyatakan bahwa lingkungan kerja berpengaruh signifikan terhadap kinerja karyawan yang menunjukkan adanya hubungan lingkungan kerja dan motivasi kerja, maka semakin nyaman dan dan menyenangkan lingkungan kerja yang dirasakan karyawan semakin tinggi pula kinerja yang dumiliki karyawan. (Siti Nurhidayah, 2018)

\section{Penghargaan (Reward) berpengaruh terhadap kinerja karyawan PT Socfindo Kebun Afdheling Seleleh Divisi IV}

Reward merupakan salah satu elemen yang dapat dimanfaatkan organisasi untuk memotivasi karyawan agar dapat memberikan kontribusi yang maksimal. Reward bisa diartikan sebagai ganjaran, hadiah, penghargaan, atau imbalan. Reward sebagai semua jenis penghargaan langsung dan tidak langsung serta intrinsik dan ekstrinsik yang mencakup gaji, kompensasi, tunjangan serta penghargaan yang bersifat intrinsik seperti pekerjaan itu sendiri, hubungan dengan rekan kerja dan atasan, pembelajaran dan pengembangan serta pengalaman kerja itu sendiri.

Hasil penelitian menunjukkan bahwa variabel penghargaan (reward) berpengaruh positif terhadap kinerja karyawan PT Socfindo Kebun Afdheling Seleleh Divisi IV. Hal ini dibuktikan dengan nilai sig dari variabel penghargaan (reward) yakni $0.002<0.05$ (tingkat signifikansi), yang artinya bahwa pengaruh yang terjadi antara variabel penghargaan (reward) dengan kinerja karyawan adalah signifikan secara statistik. Sedangkan nilai t hitung 3,257 > 2,00100 (t tabel), sehingga variabel penghargaan (reward) berpengaruh positif terhadap kinerja karyawan. Maka, dapat disimpulkan pengaruh variabel penghargaan terhadap kinerja karyawan PT Socfindo Kebun Afdheling Seleleh Divisi IV bersifat positif dan signifikan yaitu $\mathrm{H}_{\mathrm{a}} 2$ diterima dan $\mathrm{H}_{0} 2$ ditolak. Berdasarkan hasil penelitian, terlihat bahwa pemberian penghargaan (reward) berpengaruh terhadap tinggi rendahnya kinerja karyawan.

Hasil ini sesuai dengan penelitian Muhammad Ihsan dan Ismi Nur Afani (2018) yang menyatakan bahwa pemberian penghargaan (reward) mempengaruhi naik turunnya kinerja karyawan, dimana hal tersebut berarti penghargaan (reward) memiliki pengaruh langsung kinerja karyawan. Kemudian Faizal Hidayat (2017) yang dalam penelitiannya menemukan bahwa penghargaan (reward) berpengaruh terhadap kualitas kerja karyawan.

\section{Punishment berpengaruh terhadap kinerja karyawan PT Socfindo Kebun Afdheling Seleleh Divisi IV}

Punishmet adalah tindakan yang memberikan konsekuensi tidak menyenangkan yang diberikan atau ditimbulkan seseorang sesudah terjadinya pelanggaran, kesalahan, atau kejahatan. Punishmet dapat diberikan oleh manajer atau atasan yang ada diperusahaan berupa kritikan, penurunan jabatan, bahkan pemutusan hubungan kerja. 
Didalam konteks perusahaan Punishmet akan diberikan kepada karyawan yang melakukan kelalaian atau kesalahan dalam bekerja yang dapat merugikan perusahaan. Punishmet dapat berupa teguran, surat peringatan, skorsing, mutasi, maupun penghentian pekerjaan serta dapat juga pembatalan bonus dibulan terkait

Hasil penelitian menunjukkan bahwa variabel punishment berpengaruh positif terhadap kinerja karyawan PT Socfindo Kebun Afdheling Seleleh Divisi IV. Hal ini dibuktikan dari nilai sig dari variabel kinerja karyawan yakni $0.004<0.05$ (tingkat signifikansi), yang artinya bahwa pengaruh yang terjadi antara variabel punishment dengan pendapatan adalah signifikan secara statistik. Sedangkan nilai t hitung 3,638 > 2,00100 ( $\mathrm{t}$ tabel), sehingga variabel punishment berpengaruh positif terhadap kinerja karyawan. Maka, dapat disimpulkan bahwa pengaruh punishment terhadap kinerja karyawan PT Socfindo Kebun Afdheling Seleleh Divisi IV bersifat positif dan signifikan yaitu $\mathrm{H}_{\mathrm{a}} 3$ diterima dan $\mathrm{H}_{0} 3$ ditolak. Keseluruhan sistem Punishment yang telah berjalan dan diterapkan secara tepat dan bijak sehingga efek yang didapat bukanlah negatif, melainkan efek positif berupa peningkatan kinerja karyawan.

Hasil penelitian ini didukung dari penelitian Galih Dwi Koencoro (2017) yang menemukan bahwa setelah adanya pelaksanaan pemberian Punishment, kedisiplinan para karyawan semakin meningkat, dimana hal tersebut berarti Punishment memiliki pengaruh langsung terhadap disiplin karyawan yang membuat para karyawa dapat meningkatkan hasil kinerjanya.

Disamping melakukan pengujian parsial, penelitian ini menemukan hasil pengujian secara simultan yang peneliti uraikan sebagai berikut :

Uji simultan (F) bertujuan untuk mengetahui pengaruh semua variabel independen yaitu lingkungan kerja, penghargaan (reward) dan punishment terhadap kinerja karyawan PT Socfindo Kebun Afdheling Seleleh Divisi IV. Apabila nilai sig < 0,05 atau $F_{\text {hitung }}>F_{\text {tabel, }}$ maka model regresi signifikan secara statistik dapat disimpulkan bahwa $\mathrm{H}_{0}$ ditolak.

Tabel 3.

\section{Hasil Uji Simultan (Uji F)}

ANOVA $^{\mathrm{a}}$

\begin{tabular}{lllllll}
\multicolumn{1}{l}{ Model } & & Sum of & & Mean & & \\
1 & & Squares & Df & Square & F & Sig. \\
& Regression & 114,283 & 3 & 38,094 & 5,122 & ,003 $^{\text {b }}$ \\
& Residual & 438,797 & 59 & 7,437 & & \\
& Total & 553,079 & 62 & & &
\end{tabular}

a. Dependent Variable: Y

b. Predictors: (Constant), X3, X2, X1

Berdasarkan hasil tabel uji $\mathrm{F}$ diatas diperoleh nilai sig sebesar $0.003<0,05$ (tingkat signifikan $\alpha$ ) dan F hitung sebesar 4,033 serta diketahui df1=k-1=4-1=3 dan 
df2 $=\mathrm{N}-\mathrm{k}=63-4=59(\mathrm{~F}$ tabel= 2,76). Sehingga $\mathrm{F}$ hitung $>\mathrm{F}$ tabel $(5,122>2,76)$, maka $\mathrm{H}_{\mathrm{a}} 4$ diterima dan $\mathrm{H}_{0} 4$ ditolak yang artinya teradapat pengaruh signifikan antara variabel bebas terhadap variabel terikat. Jadi dapat disimpulkan bahwa lingkungan kerja, penghargaan (reward) dan punishment secara simultan berpengaruh signifikan terhadap kinerja karyawan PT Socfindo Kebun Afdheling Seleleh Divisi IV.

\section{Tabel 4.}

\section{Hasil Uji Koefisien Determinasi $\left(\mathbf{R}^{2}\right)$}

\section{Model Summary}

\begin{tabular}{|c|c|c|c|c|}
\hline & & $\mathrm{R}$ & Adjusted R & \\
\hline Model & $\mathrm{R}$ & Square & Square & Std. Error of the Estimate \\
\hline 1 & $455^{\mathrm{a}}$ & ,207 &, 774 & 2,727 \\
\hline
\end{tabular}

Berdasarkan Tabel diatas, dapat diketahui bahwa hasil nilai dari Adjusted $R$ Square (adjusted $\mathrm{R}^{2}$ ) adalah sebesar 0,774. Nilai koefisien determinasi menunjukkan bahwa kinerja karyawan PT Socfindo Kebun Afdheling Seleleh Divisi IV dipengaruhi sangat kuat oleh variabel lingkungan kerja (X1), penghargaan (reward) (X2) dan

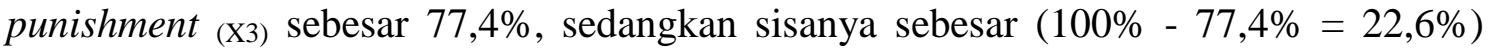
dijelaskan oleh variabel lain yang tidak termasuk dalam penelitian ini.

\section{KESIMPULAN}

Berdasarkan hasil analisa data-data hasil penelitian pada penelitian ini, maka dapat peneliti simpulkan hasil penelitian ini adalah sebagai berikut:

Secara parsial lingkungan kerja, penghargaan (reward) dan punishment berpengaruh positif terhadap kinerja karyawan PT Socfindo Kebun Afdheling Seleleh Divisi IV. Sedangkan secara simultan lingkungan kerja, penghargaan (reward) dan punishment berpengaruh secara Simultan terhadap kinerja karyawan PT Socfindo Kebun Afdheling Seleleh Hasil penelitian menunjukkan bahwa nilai sig sebesar $0.003<$ 0,05 (tingkat signifikan $\alpha$ ) dan F hitung $>\mathrm{F}$ tabel $(5,122>2,76)$.

Adapun saran-saran peneliti dalam penelitian ini adalah sebagai berikut: Sistem reward yang diterapkan Perusahaan PT Socfindo Kebun Afdheling Seleleh Divisi IV sekarang sudah berjalan dengan baik. Bagi perusahaan diharapkan untuk tetap mempertahankan sistem reward tersebut atau bahkan menambahkan beberapa reward baru untuk semakin meningkatkan kinerja karyawan.Sistem Punishment atau hukuman yang diterapkan oleh pihak perusahaan PT Socfindo Kebun Afdheling Seleleh Divisi IV sekarang sudah berjalan dengan dengan efektif. Bagi pihak perusahaan diharapkan untuk tetap memperhatikan pentingnya memberikan teguran atau bahkan hukuman kepada karyawan yang tidak menaati peraturan perusahaan. 


\section{DAFTAR PUSTAKA}

Ahmad Tanzeh. (2011). Metodologi Penelitian Praktis, Yogyakarta: Teras.

Anwar Prabu. (2013). Mangkunegara, Manajemen Sumber Daya Manusia Perusahaan, Bandung: Remaja Rosda Karya.

Arikunto. (2002). Prosedur Pene ynalitian : Suatu Pendekatan Praktek, Edisi Revisi, Jakarta: PT Rineka Cipta.

Azuar Juliandi dan Irfan. Metodologi Penelitian Kuantitatif Untuk Ilmu-Ilmu Bisnis, Bandung: Ciptapustaka Media Printis

BPS Survei perkebunan, 2019. http://bps.go.id (diakses pada 27 Oktober 2020).

Budiman, I., Kamal, S., \& Tarlis, A. (2019). Strategi Pemerintah Daerah Kota Langsa Povinsi Aceh dalam Mengembangkan Obyek Wisata Halal. Jurnal Samudra Ekonomi Dan Bisnis. https://doi.org/10.33059/jseb.v11i1.1659

DIRJENBUN. (2019) Statistik perkebunan indonesia komoditas kelapa sawit 20152019, (Jakarta : Kementrian Pertanian), diakses pada 27 Oktober 2020

Galih Dwi Koencoro. (2013). pengaruh Reward dan Punishment terhadap kinerja, Malang: Universitas Brawijaya.

Hani T.Handoko. (2000). Manajemen Personalia Dan Sumber Daya Manusia, Yogjakarta: BPFE.

Hendri Tanjung dan Abrista Devi. Metodologi Penelitian Ekonomi Islam, Jakarta: Gramata Publishung.

Husein Umar. (2008). Metodologi Penelitian Untuk Skripsi dan Tesis Bisnis, Jakarta: Raja Grafindo.

Imam Ghozali (2005). Aplikasi Analisis Multivariate dengan Program SPSS, (Semarang: Badan Penerbit UNDIP.

Kadarisman M. Manajemen Pengembangan Sumber Daya Manusia, Jakarta: PT Raja Grafindo Persada

Kamsir. (2004). Manajemen Perbankan, Jakarta: PT. Raja Grafindo Persada cet ke-4.

Mahsun, Mohammad. (2006). Pengukuran Kinerja Sektor Publik, Yogyakarta: BPFE.

Mangkunegara. (2012). Perilaku dan Budaya Organisasi (Cetakan Pertama), Bandung: PT Refika Aditama.

Mangkuprawira dan Hubeis.(2007) Manajemen Mutu Sumber Daya Manusia, Bogor: Ghalia Indonesia.

Martuyo, Susilo (2017). Manajemen Sumber Daya Manusia Edisi 5 Cetakan Petama, Yogyakarta: BPFE.

Masram dan Mu'ah. (2017). Manajemen Sumber Daya Manusia Profesional, Sidoarjo: Zifatama Publisher.

Moeheriono. (2012). Pengukuran Kinerja Berbasis Kompetensi, Jakarta: Raja Grafindo, 2012. 
Muhamad. (2008). Metodologi Penelitian Ekonomi Islam Pendekatan Kuantitatif, Jakarta: PT Rajagrafindo Persada.

Murtianingsih. Globalisasi Dan Korelasinya Dengan Industri Manufaktur Yang Merupakan Leading Sector Perekonomian, dalam jurnal JIBEKA XI (2): 33-39, Agustus 2015.

Nitisemito. (2012). Manajemen Personalia (Manajemen Sumber Daya Manusia), Yogyakarta: Ghalia Indonesia.

PT.Socfin Indonesia, www.socfindo.com (diakses pada 16 April 2020).

Puwanenthiren, (2011). P, "Reward System and its Impact on Employee Motivation in Commercial Bank of Sri Lanka Plc, In Jaffna District" Global Journal of Management and Business Research, XI (14).

Raja Ali, dkk, (2011). Analisis Reward dan Punishment Pada Kantor Perum Damri Makassar, Makassar : UNHAS.

Rivai, Veithzal. (2005). Manajemen Sumber Daya Manusia Untuk Perusahaan, Dari Teori Ke Praktek, Jakarta: PT. Rajagrafindo Persada.

Sugiyono. (2011). Metode Penelitian Administrasi, Cet. Ke-19, Bandung: Alfabeta.

Sugiyono. (2008). Metode Penelitian Bisnis, Bandung: Alfabeta.

Sugiyono. (2012) Metodologi Penelitian Pendidikan Pendekatan Kuantitatif, Kualitatif dan $R \& D$, Bandung: Alfabeta.

Suharyanto dan Purwanto SK. (2004). Statistik Untuk Ekonomi Dan Keuangan Moderen, Jakarta: Salempa Empat.

Sujarweni, V. Wiratma dan Poly Endrayanto. (2012) Statistik Untuk Penelitian, Yogyakarta: Graha Ilmu.

Suryadi prawirosentono. (1999). Manajemen Sumber Daya Manusia Kebijakan Kinerja Karyawan, Yogyakarta: BPFE. 